\title{
Competition for feed affects the feeding behavior of growing dairy heifers
}

\author{
T. J. DeVries*1 and M. A. G. von Keyserlingk† \\ *Department of Animal and Poultry Science, University of Guelph, Kemptville Campus, Kemptville, Ontario, K0G 1J0, Canada \\ †Animal Welfare Program, The University of British Columbia, Vancouver, British Columbia, V6T 1Z4, Canada
}

\section{ABSTRACT}

The objective of this study was to determine how competition for feed influences the feeding behavior of young, growing dairy heifers. Thirty-six prepubertal Holstein heifers $(231.5 \pm 12.1 \mathrm{~d}$ old, weighing $234.7 \pm$ $24.0 \mathrm{~kg}$ ), consuming a total mixed ration ad libitum, were assigned to 1 of 2 treatments: noncompetitive (1 heifer/feed bin), or competitive (2 heifers/feed bin). After $7 \mathrm{~d}$ of treatment adaptation, dry matter intake and feeding behavior were monitored for $7 \mathrm{~d}$ for each animal. Fresh feed and orts were sampled on the last 3 $\mathrm{d}$ of the treatment period from each bin and were subjected to particle size analysis. The particle size separator consisted of 3 screens $(18,9$, and $1.18 \mathrm{~mm})$ and a bottom pan resulting in 4 fractions (long, medium, short, and fine). Sorting activity for each fraction was calculated as the actual intake expressed as a percentage of the predicted intake. There was no difference in sorting behavior or dry matter intake between the treatments. Overall, the heifers sorted against long particles (94\%), and sorted for medium (102\%) and short (103\%) particles. The competitively fed heifers tended to have $10 \%$ shorter feeding times, particularly at peak feeding periods. The competitively fed heifers also consumed $9 \%$ fewer meals per day, although the duration of these meals were $10 \%$ longer, and tended to be $13 \%$ larger. Competition for feed also tended to increase the day-to-day variation in feeding time, meal duration, and meal size. It can be concluded that competition for feed for growing dairy heifers alters feeding patterns, reduces access to feed, particularly during periods of peak feeding activity, and tends to increase day-to-day variation in feeding behavior.

Key words: dairy heifer, competition, feeding behavior

Received November 27, 2008.

Accepted March 31, 2009.

${ }^{1}$ Corresponding author: tdevries@kemptvillec.uoguelph.ca

\section{INTRODUCTION}

There is growing interest in the feeding management strategies for growing dairy heifers. One feeding strategy that has received increased attention is limit feeding of replacement heifers (Hoffman et al., 2007). Limiting feed intake has been shown to slow the rate of passage, which results in greater retention time, and ultimately causes increased ruminal digestibility and nutrient utilization (Tamminga et al., 1979; Loerch, 1990). In a limit-fed situation, animals are provided insufficient quantities of feed to allow heifers to express behavior closer to natural foraging. Limit-feeding not only reduces the amount of time cattle spend eating (Hoffman et al., 2007), but also reduces the amount of time feed is available for consumption (Longenbach et al., 1999). Under natural grazing conditions, cattle will engage in foraging behavior for 4 to $9 \mathrm{~h}$, distributing their feeding time throughout the day (Hafez and Bouissou, 1975). To satisfy this natural feeding behavior of these animals, an alternative approach to limit feeding is to decrease the nutrient density of a feed and allow ad libitum access (Hoffman et al., 1996). In a recent study, Greter et al. (2008) reported that ad libitum feeding of a nutrient diluted diet might help reduce feed costs, enable producers to target caloric intake for desirable weight gain and growth, and allow the heifers to express their natural foraging behavior.

A potential drawback of feeding a diluted diet, as found by Greter et al. (2008), is increased sorting of the highly fermentable, high-energy small particle fractions of the ration. This type of sorting behavior may put heifers at increased risk for consuming an unbalanced diet, and may also increase the risk of ruminal acidosis (DeVries et al., 2008). These risks may be exacerbated under management conditions that promote competition for feed. In a recent study on close-up dry cows it was found that competition for feed changed the distribution of DMI over the course of the day, resulting in higher intakes during the later hours after feed delivery, when much of the feed sorting had already occurred (Hosseinkhani et al., 2008). Further, it has been shown that at higher stocking densities, subordinate cows are most limited in their access to the feed bunk during times of peak feeding activity following feed delivery 
Table 1. Chemical composition and particle size distribution of the TMR

\begin{tabular}{lc}
\hline Composition & TMR \\
\hline Ingredient, \% of DM & \\
Corn silage & 15.3 \\
Grass silage $^{\text {Concentrate }}{ }^{1}$ & 47.0 \\
Rye straw $_{\text {Chemical composition }}^{2}$ & 27.9 \\
DM, \% & 9.8 \\
CP, \% of DM & $44.6 \pm 5.1$ \\
ADF, \% of DM & $15.8 \pm 0.5$ \\
NDF, \% of DM & $27.4 \pm 1.8$ \\
OM, \% of DM & $43.8 \pm 2.8$ \\
Particle size distribution, \% of DM retained on sieve & \\
Long & $91.8 \pm 0.7$ \\
Medium & $30.4 \pm 5.8$ \\
Short & $44.5 \pm 5.1$ \\
Fine & $21.2 \pm 5.0$ \\
\hline
\end{tabular}

${ }^{1}$ Textured heifer grower supplied by Unifeed Ltd. (Chilliwack, British Columbia, Canada), containing (on as-is basis): $15.0 \%$ flatted corn, $14.0 \%$ canola meal, $12.9 \%$ ground wheat, $11.6 \%$ soymeal, $10.2 \%$ mixed grains, $9.0 \%$ flatted oats, $8.4 \%$ millrun, $7.0 \%$ flatted barley, $4.8 \%$ molasses, $2.3 \%$ calcium carbonate, $1.6 \%$ ground barley, $1.3 \%$ salt, $0.7 \%$ dicalcium phosphate, $0.6 \%$ ground alfalfa pellets, $0.3 \%$ ground corn, $0.2 \%$ trace mineral/vitamin premix, $0.07 \%$ lasolacid sodium (Bovatec, Alpharma Canada Corp., Mississauga, Ontario, Canada).

${ }^{2}$ Values were obtained from chemical analysis of feed samples.

${ }^{3}$ Particle size determined by Penn State Particle Separator, which has a 19-mm screen (long), 8-mm screen (medium), 1.18-m screen (short), and a pan (fine).

(DeVries et al., 2004). These results would suggest that in high stocking densities, the between-cow variation in composition of TMR consumed would increase.

Previous research on the effects of stocking density on the behavior of dairy heifers has been restricted to those that are limit fed (Keys et al., 1978; Longenbach et al., 1999). To date, little is known about how competition may influence feed access and feed sorting in ad libitum-fed prepubertal dairy heifers. The objective of this research was to determine the effect of competition for feed on the feeding behavior of growing dairy heifers. We hypothesized that competition for feed will negatively affect feeding behavior by decreasing feeding time, increasing the amount of feed sorting, and shifting the diurnal patterns of DMI.

\section{MATERIALS AND METHODS}

\section{Animals and Housing}

Thirty-six Holstein heifers were used in the study. The animals were $231.5 \pm 12.1$ (mean $\pm \mathrm{SD}$ ) days old, weighed $234.7 \pm 24.0 \mathrm{~kg}$, and were $111.1 \pm 3.7 \mathrm{~cm}$ high at the withers at the beginning of their respective data collection periods. The animals, on average, gained 1.1 $\pm 0.6 \mathrm{~kg} / \mathrm{d}$ and grew $0.3 \pm 0.3 \mathrm{~cm} / \mathrm{d}$ during the study period. The animals were housed in the heifer research barn at The University of British Columbia Dairy Education and Research Centre (Agassiz, BC, Canada) and were managed according to the guidelines set by the Canadian Council on Animal Care (1993).

Heifers were housed in a pen that consisted of a sawdust bedded-pack area $(9.2 \times 9.0 \mathrm{~m}$ each $)$ and a standing alley $(9.2 \times 3.05 \mathrm{~m})$ which divided the pack from the feeding area. The animals had ad libitum access to feed, which was provided using 6 roughage intake control feed bins (Insentec BV, Marknesse, the Netherlands). Each individual feed bin was $0.8 \mathrm{~m}$ wide, $0.75 \mathrm{~m}$ high, and had a depth of $0.74 \mathrm{~m}$. Water was available ad libitum to the heifers through 2 water bowls in the pen.

The TMR was formulated according to the NRC (2001) nutrient requirement recommendations for a 250-kg nonbred Holstein heifer growing at $1.0 \mathrm{~kg} / \mathrm{d}$ (Table 1). The heifers were fed twice per day at 0800 and $1600 \mathrm{~h}$. Orts were removed from the feed bins each day at 0730 and $1530 \mathrm{~h}$. To ensure ad libitum DMI and observation of sorting, the amount of feed offered per feeding to each animal was adjusted daily to target $15 \%$ orts. The actual orts averaged $17.4 \pm 9.8$ (mean $\pm \mathrm{SD}) \% \mathrm{DM}$ of offered feed over the course of the experiment.

\section{Experimental Design}

The heifers were split into 4 groups of 9 , which were balanced for age and weight at the start of data collection for each group. Heifers within each group were alternately assigned to 1 of 2 treatments: a noncompetitive treatment in which heifers had exclusive access to one bin (1 heifer/feed bin) or a competitive treatment in which 2 heifers shared an individual feed bin (2 heifers/feed bin). Thus, within each group of 9 , there were 3 heifers on the noncompetitive treatment $(n=3$ feed bins) and 6 heifers (in 3 pairs) on the competitive treatment ( $\mathrm{n}=3$ feed bins). The design of the feeding system allowed for each heifer to be electronically assigned and restricted to an individual feed bin (Chapinal et al., 2007). Thus, individual heifers on the noncompetitive treatment were trained to eat from a single feed bin, while each pair of heifers in the competitive treatment was trained to eat from a single feed bin. To reduce any effect of bin location, treatments were assigned alternately to each feed bin within the pen.

Each group of animals was housed together for 7 $\mathrm{d}$ before the data collection period to allow for social adaptation and facilitate training to their specific feed bins. Immediately following this habituation period, the animal remained on treatment for $7 \mathrm{~d}$ for data collection. Groups were run sequentially; the first group was introduced on September 6, 2007, and the last group completed the experiment on November 1, 2007. 
Table 2. Chemical composition and particle size distribution of the forages (mean $\pm \mathrm{SD}$; DM basis)

\begin{tabular}{lrrr}
\hline Item & Corn silage & Grass silage & Rye straw \\
\hline Chemical composition $^{1}$ & & & \\
DM, \% & $30.4 \pm 5.0$ & $37.9 \pm 2.8$ & $89.1 \pm 0.8$ \\
CP, \% & $7.8 \pm 0.6$ & $18.3 \pm 1.0$ & $5.7 \pm 0.6$ \\
ADF, \% & $28.3 \pm 3.1$ & $32.1 \pm 0.9$ & $46.7 \pm 1.3$ \\
NDF, \% & $46.7 \pm 3.4$ & $51.7 \pm 1.2$ & $70.9 \pm 1.3$ \\
OM, \% & $95.0 \pm 0.8$ & $90.2 \pm 0.1$ & $94.9 \pm 0.4$ \\
Particle size distribution, \% of DM retained on sieve ${ }^{2}$ & & & \\
Long & $12.4 \pm 2.3$ & $42.8 \pm 8.9$ & $59.5 \pm 5.7$ \\
Medium & $72.8 \pm 1.7$ & $47.4 \pm 7.0$ & $28.5 \pm 4.1$ \\
Short & $14.1 \pm 3.6$ & $8.7 \pm 1.4$ & $10.3 \pm 1.3$ \\
Fine & $0.7 \pm 0.7$ & $1.1 \pm 0.6$ & $1.7 \pm 0.2$ \\
\hline
\end{tabular}

${ }^{1}$ Values were obtained from chemical analysis of feed component samples.

${ }^{2}$ Particle size determined by Penn State Particle Separator, which has a 19-mm screen (long), 8-mm screen (medium), 1.18-mm screen (short), and a pan (fine).

\section{Measuring Feed Intake and Behavior}

The Insentec feed bins (Insentec BV), as validated by Chapinal et al. (2007) and described by Huzzey et al. (2007), continuously measured feeding behavior as well as individual feed intake for all experimental animals. From the recorded data, we were able to determine the duration of each visit to the feed bin, the amount of feed consumed (start weight - end weight) during each visit, and the rate of consumption for each visit. These data were then summarized to calculate daily DMI $(\mathrm{kg} / \mathrm{d})$, daily time spent feeding $(\mathrm{min} / \mathrm{d})$, and average feeding rate $(\mathrm{kg} / \mathrm{min})$ for each heifer.

\section{Meal Analysis}

Visits to the feed intake system were clustered into meals using meal criteria (minimum time interval that a heifer is away from the feed bin to be considered a meal). For each heifer, the time intervals between feeding bouts across the $7 \mathrm{~d}$ of the data collection period were computed, $\log _{10}$ transformed, and plotted in a frequency distribution. Meal criteria were then calculated for each heifer using a mixed distribution model, as outlined by Tolkamp et al. (1998) and DeVries et al. (2003). Across all heifers used in the study, meal criteria averaged $29.8 \pm 4.8$ (mean $\pm \mathrm{SD}$ ) minutes. Using the criteria determined for each heifer, meal frequency, duration, and size were calculated.

\section{Feed Sampling and Analysis}

Representative samples of the TMR were collected for particle size separation on d 5, 6, and 7 of each treatment period at the time of the a.m. feed delivery. Samples of the TMR were taken at the time of the a.m. and p.m. feed delivery on d 5 of each treatment period for DM and chemical analysis. Given the findings of
Hosseinkhani et al. (2008), sorting was only measured between the first and second feedings. As such, orts samples for particle size separation, and thus measurement of sorting, were taken from each feed bin during clean out at $1530 \mathrm{~h}$ on d 5, 6, and 7 during each treatment period. Additionally, on d 5 of each treatment period, duplicate samples of the diet components were taken for particle size analysis and chemical analysis (Table 2). All samples were immediately frozen at $-20^{\circ} \mathrm{C}$ until further analysis.

Samples for particle size separation were separated using the 3-screen (19, 8, and $1.18 \mathrm{~mm})$ Penn State Particle Separator (PSPS; Kononoff et al., 2003). This separated the particles into 4 fractions: long $(>19 \mathrm{~mm})$, medium $(<19,>8 \mathrm{~mm})$, short $(<8,>1.18 \mathrm{~mm})$ and fine $(<1.18 \mathrm{~mm})$ particles. After separation, the DM of each separated fraction was determined by oven drying at $55^{\circ} \mathrm{C}$ for $48 \mathrm{~h}$.

Samples taken for DM and chemical analysis were oven-dried at $55^{\circ} \mathrm{C}$ for $48 \mathrm{~h}$ and then ground to pass through a 1-mm screen (Brinkmann Mill, Brinkmann Instruments Co., Westbury, NY). These samples were sent to Cumberland Valley Analytical Services Inc. (Maugansville, $\mathrm{MD})$ for analysis of $\mathrm{DM}\left(135^{\circ} \mathrm{C}\right.$; AOAC, 2000; method 930.15), ash $\left(535^{\circ} \mathrm{C}\right.$; AOAC, 2000; method 942.05), ADF (AOAC, 2000; method 973.18), NDF with heat-stable $\alpha$-amylase and sodium sulfite (Van Soest et al., 1991), and CP $(\mathrm{N} \times 6.25$; AOAC 2000; method 990.03; Leco FP-528 Nitrogen Analyzer, Leco, St. Joseph, MI).

\section{Calculations and Statistical Analysis}

The DMI and feeding behavior data were summarized on an individual feed bin basis; that is, the data for individual heifers sharing a bin in the competitive treatment were averaged to create a single value per bin. Similarly, sorting was calculated on a bin basis. Sorting 
was calculated as the actual DMI of each fraction of the PSPS expressed as a percentage of the predicted DMI of that fraction (Leonardi and Armentano, 2003). The actual intake of each individual fraction was calculated as the difference between the DM amount of each fraction in the offered TMR and that in the refused feed. The predicted intake for each individual fraction was calculated as the product of the DMI of the total diet multiplied by the DM percentage of that fraction in the feed provided to the heifer. Values equal to $100 \%$ indicate no sorting, $<100 \%$ indicate selective refusals (sorting against), and $>100 \%$ indicate preferential consumption (sorting for).

For all analyses, the individual feed bin was considered as the experimental unit. Preliminary screening of the data revealed that all dependent variables were normally distributed. To test whether sorting occurred, sorting for each fraction of the PSPS was summarized by bin and tested for a difference from 100 using $t$-tests within the Mixed procedure of SAS (SAS Institute, 2003). A preliminary analysis of the effect of day within treatment period was conducted for the DMI, feeding behavior, and feed sorting data. This analysis revealed no day effect and therefore the data were averaged across treatment period for each feed bin. Homogeneity of variance tests (Levene's test in the GLM procedure of SAS) were performed on all data; all tests gave $P>$ 0.31 , indicating that variances were sufficiently comparable to test for differences. The sorting data, plus the DMI and feeding behavior data were then analyzed using the Mixed procedure of SAS. The model included the fixed effect of treatment, the random effect of group, and the residual error [ = feeding bin(treatment $\times$ group)]. Group was considered random in this model after a preliminary analysis that revealed no significant effect of group as a fixed effect. To analyze whether competition for feed affected the day-to-day variation in DMI and feeding behavior, the standard deviation of these measures (over the $7 \mathrm{~d}$ of data collection) were calculated for each heifer within each treatment. These standard deviations were averaged for each pair within the competitive treatment, to create a single value for each feed bin (experimental unit). The standard deviations were then compared between treatments using the previously described statistical model. Data for DMI, feeding time, and feeding rate were also summarized on an hourly basis for each animal (average per bin) on each treatment. Differences among treatments in the distribution of these variables over a 24 -h period were analyzed using the Mixed procedure of SAS treating hour as a repeated measure. The model included the fixed effects of hour, treatment, and hour by treatment interaction, the random effect of group and the residual error. Feeding bin(treatment $\times$ group) was included in the model as the subject of the repeated statement. The heterogeneous first-order autoregressive covariance structure was selected based on best fit according to Schwarz's Bayesian information criterion. All values reported are least squares means. Significance was declared at $P \leq 0.05$ and tendencies were discussed at $0.05<P \leq 0.10$.

\section{RESULTS}

There was no difference in daily DMI between those heifers fed noncompetitively compared with those fed competitively (Table 3). However, the analysis of the diurnal pattern of DMI did show a treatment by hour interaction $(P<0.001$; Figure 1a). This interaction reflects the reduced DMI of the competitively fed heifers during the periods of peak feeding activity following feed delivery and higher DMI in the hours following these periods. Despite this, heifers fed competitively tended to have shorter daily feeding times compared with the heifers fed noncompetitively (Table 3). Further, there was a tendency for day-to-day variation in feeding time to be greater for the competitively fed heifers. A treatment by hour interaction $(P<0.001$; Figure 1b) in the hourly analysis of feeding time reflected the higher feeding times of the noncompetitively fed heifers during the periods of peak feeding activity and the higher feeding times of the competitively fed heifers in the hours following these periods. The differences in hourly DMI and feeding times translated into competitively fed heifers consuming their ration at a faster rate throughout most of the day $(P<0.001$; Figure 1c).

The frequency of meals consumed by the competitively fed heifers was lower, whereas the duration of these meals were longer compared with the noncompetitively fed heifers (Table 3 ). There was also a tendency for the meal size to be larger for the competitively fed heifers compared with the heifers on the noncompetitive treatment. The day-to-day variation in meal duration was greater for the competitively fed heifers, and there was a tendency for the day-to-day variation in meal size to be greater in these animals (Table 3 ).

Across treatments, heifers sorted $(P<0.05)$ against long particles $(93.8 \pm 1.8 \%)$ and for medium (102.2 \pm $0.5 \%)$ and short $(102.8 \pm 1.0 \%)$ particles. Heifers did not sort for or against fine particles $(100.2 \pm 1.4 \%)$. There was no difference in the extent of sorting between the competitive and noncompetitive treatments.

\section{DISCUSSION}

Competition for feed had no effect on the daily DMI of the heifers. This was not surprising, given 
Table 3. Intake and feeding behavior measures (means and standard deviations) for growing dairy heifers fed noncompetitively and competitively ${ }^{1}$

\begin{tabular}{|c|c|c|c|c|}
\hline Item & Noncompetitive $^{2}$ & Competitive & $\mathrm{SE}$ & $P$-value \\
\hline \multicolumn{5}{|c|}{ DMI, kg/d } \\
\hline Mean & 6.20 & 6.27 & 0.30 & 0.77 \\
\hline SD & 0.64 & 0.69 & 0.10 & 0.69 \\
\hline \multicolumn{5}{|c|}{ Feeding time, $\min / \mathrm{d}$} \\
\hline Mean & 212.5 & 191.8 & 7.8 & 0.08 \\
\hline SD & 17.6 & 23.0 & 2.0 & 0.08 \\
\hline \multicolumn{5}{|c|}{ Feeding rate, $\mathrm{g}$ of $\mathrm{DM} / \mathrm{min}$} \\
\hline Mean & 37.7 & 46.7 & 3.9 & 0.12 \\
\hline SD & 7.1 & 10.4 & 1.7 & 0.13 \\
\hline \multicolumn{5}{|c|}{ Meal frequency, meals/d } \\
\hline Mean & 7.46 & 6.83 & 0.23 & 0.03 \\
\hline SD & 1.41 & 1.45 & 0.12 & 0.75 \\
\hline \multicolumn{5}{|c|}{ Meal duration, min/meal } \\
\hline Mean & 52.7 & 62.9 & 2.2 & 0.003 \\
\hline SD & 12.0 & 17.4 & 1.2 & 0.005 \\
\hline \multicolumn{5}{|c|}{ Meal size, $\mathrm{g}$ of DM/meal } \\
\hline Mean & 866.2 & 980.3 & 67.7 & 0.07 \\
\hline SD & 183.7 & 257.1 & 25.8 & 0.06 \\
\hline
\end{tabular}

${ }^{1}$ Data are averaged per feed bin (expressed on a per animal basis) over $7 \mathrm{~d}$ for 12 feed bins on each treatment. Standard deviations indicate day-to-day variation (across $7 \mathrm{~d}$ of each period), calculated for each animal and averaged per feed bin.

${ }^{2}$ Noncompetitive $=1$ heifer $/$ feed bin; competitive $=2$ heifers $/$ feed bin.

that experiments on feeding competition have generally reported no (González et al., 2008b; Hosseinkhani et al., 2008) or very little (Olofsson, 1999) effect on daily DMI. However, we did note differences in feeding behavior. The competitively fed heifers tended to have $10 \%$ shorter daily feeding times. This supports previous findings by Olofsson (1999) and Hosseinkhani et al. (2008) that time at the feeder decreases (by 19 and $10 \%$, respectively) when competition is increased (from 1 to 4 cows/feed bin and 1 to 2 cows/feed bin, respectively) in TMR-fed adult cows. In studies on limitfed heifers, decreases in feeding time have also been reported. Keys et al. (1978) found that decreasing feed bunk space (from 0.81 to $0.20 \mathrm{~m} /$ heifer) for yearling heifers linearly decreased their time spent eating by $26 \%$. Longenbach et al. (1999) reported that heifers of similar age to those used in the present study, subjected to increasing competition (by reducing feed bunk space from 31 to $15 \mathrm{~cm} /$ heifer), spent $50 \%$ less time eating. In the present study, the competitively fed heifers had $9 \%$ fewer meals per day, which tended to be $13 \%$ larger and were $10 \%$ longer in duration. Dissimilar to our results, Longenbach et al. (1999) found that increasing competition at the feed bunk in limit-fed heifers increased meal frequency by $71 \%$ and decreased meal length by $56 \%$. Olofsson (1999) also found that increasing competition from 1 to 4 cows/feed bin increased meal frequency by $22 \%$. These discrepancies in results are likely the result of differences in meal calculation. Longenbach et al. (1999) used a very short meal criterion (40 s), with no apparent justification for its determination. Olofs- son (1999) also used a short meal criterion (5 min), which was calculated using a log-survivorship curve. In the present study, meal criteria were calculated using a mixed distribution model. This methodology allows for the identification of a more biologically relevant meal criterion for the feeding behavior of dairy cows, and thus a more objective basis for calculations of mealbased measures of feeding behavior (Tolkamp et al., 1998).

Contrary to our hypothesis and similar to previous work on cows (Hosseinkhani et al. 2008), competition for feed did not affect the degree of feed sorting. Similar to Greter et al. (2008), all heifers in this study did sort against the longest particles (6\% refusal), and sorted for the medium and short particles (2 to $3 \%$ selection for). Given the particle size distribution of the forages, it is clear that the heifers were primarily sorting against the long rye straw and grass silage particles. The main components in the medium particle fraction were flattened corn and short forage particles, whereas the pellets and other grain portions of the concentrate made up the majority of the short particles. The animals, therefore, were likely sorting for the highly palatable concentrate components of their ration as well as those smaller particles that could be more quickly consumed (Pyke et al., 1977; Campling and Morgan, 1981). The level of overfeeding, as reflected in the percentage of orts, was higher than that which is typically done to ensure ad libitum intake, and may have slightly exacerbated the degree of sorting (Leonardi and Armentano, 2007). 

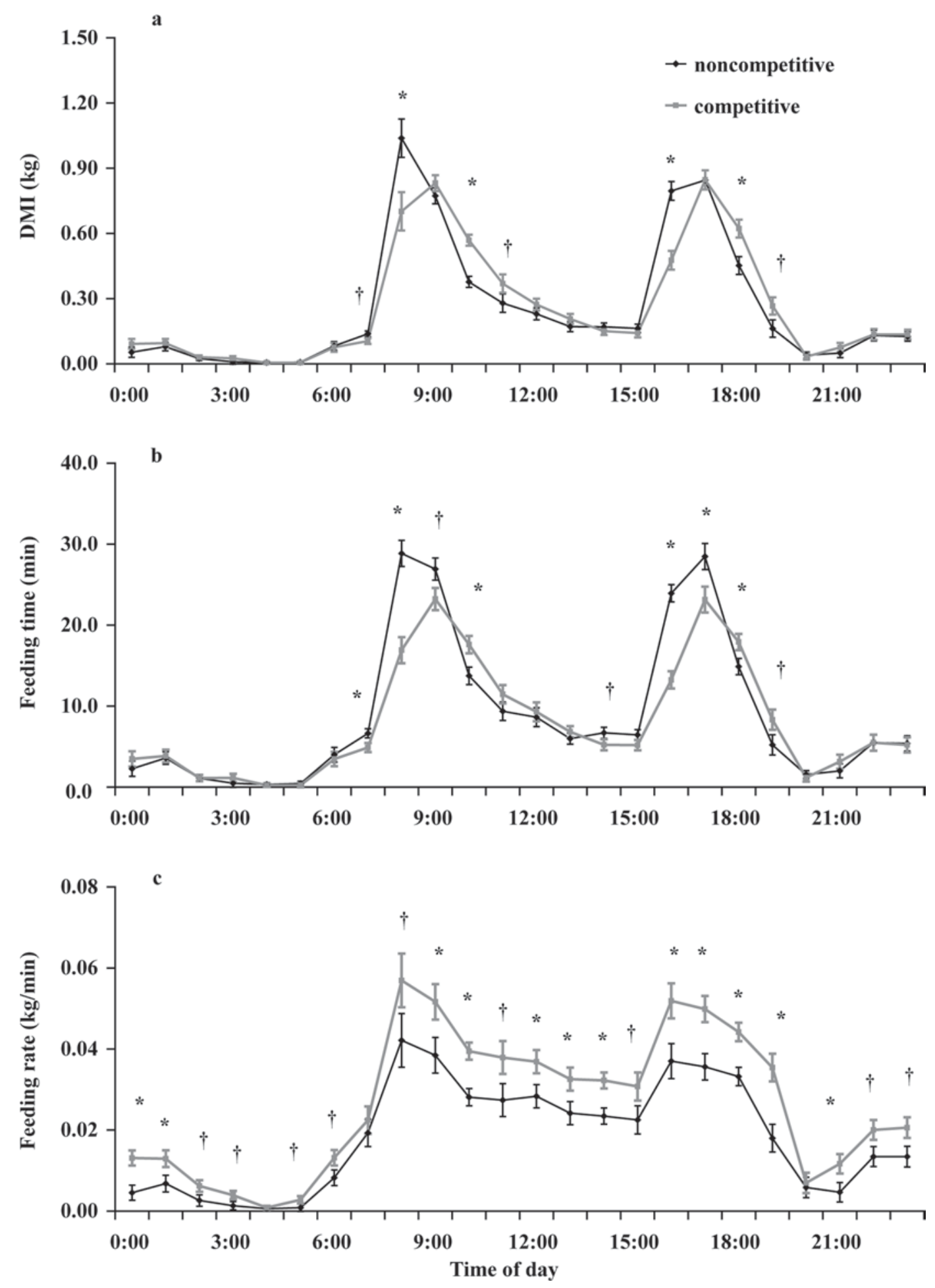

Figure 1. Hourly averages for a) DMI ( $\mathrm{kg})$, b) feeding time ( $\mathrm{min})$, and c) feeding rate $(\mathrm{kg} / \mathrm{min})$ for growing dairy heifers fed noncompetitively ( 1 heifer/feed bin) or competitively ( 2 heifers/feed bin). Data are averaged per feed bin (expressed on a per animal basis) over $7 \mathrm{~d}$ for 12 feed bins on each treatment. $\dagger P<0.10,{ }^{*} P<0.05$. 
Given that sorting against long fiber particles has been associated with lower rumen $\mathrm{pH}$ (i.e., when $10 \%$ of long particles in the offered TMR are refused, maximum $\mathrm{pH}$ is reduced by 0.2 units; DeVries et al., 2008) and that $\mathrm{pH}$ declines increase with meal size (Allen, 1997), the large and long meals in the competitive treatment combined with sorting against long particles may negatively affect rumen fermentation. Despite not assessing rumen $\mathrm{pH}$ in this study, recent evidence supports this hypothesis. González et al. (2008b), using several physiological indicators of rumen acidosis, assessed the effect of feed bunk competition $(2,4$, or 8 heifers/feeding bin) on heifers fed a highly fermentable ration. This competition resulted in increased serum haptoglobin levels, particularly in the most subordinate animals (from 175 to $242 \mathrm{mg} / \mathrm{L}$ ) and increased the proportion of abscessed livers (from 8 to 20\%). Rumen fermentation measures, including $\mathrm{pH}$ and lactate, also indicated a greater incidence of ruminal acidosis with increasing competition. Alternatively, the increased daily time spent eating through reduced competition for feed may increase total salivary secretion (Beauchemin et al., 2008) and thus be beneficial for rumen fermentation (Owens et al., 1998). Further research is needed to assess how competition for an ad libitum-fed TMR influences the rumen fermentation patterns of growing dairy heifers.

Interestingly, the diurnal analysis of feeding behavior demonstrated that individual feed intake and feeding time were lower for the competitively fed heifers during the peak feeding period following feed delivery, but were slightly higher in the following hours. Such changes in diurnal feeding behavior in response to competition are similar to that found for dry cows consuming TMR (Hosseinkhani et al., 2008) as well as heifers consuming concentrate (González et al., 2008a,b). In the present study, given that 2 heifers shared a feeding bin in the competitive treatment, this meant that much more DM disappeared from those bins and that the feed bin was occupied for a much longer period per hour of the day compared with the bins used to feed the noncompetitive animals, particularly during hours of peak feeding activity. Thus, to maintain similar DMI, the competitively fed heifers compensated by eating faster than the noncompetitively fed heifers throughout the day, particularly during periods of peak feeding activity, and shifting their intake patterns (González et al., 2008a).

Competition for feed also increased the day-to-day variation in meal duration and tended to increase dayto-day variation in feeding time and meal size. This would indicate that the heifers within the competitive pairs were not able to maintain the same level of consistency in feeding behavior patterning as compared with those without competition for feed. González et al. (2008b) also found that the variability in eating time and final BW tended to increase in groups of heifers fed competitively, suggesting disparity between group members as far as their ability to access feed and maintain DMI. Similarly, Longenbach et al. (1999) reported that competition increased the variability in live weight gain within pens of growing dairy heifers that were limit fed. The variability observed in these previous studies can be explained by certain animals dominating the feed bunk and consuming excess DM, while reducing the amount of feed available to subordinate animals, which are most limited in access to feed during periods of peak feeding activity (DeVries et al., 2004). Similarly, sorting of the diet can reduce the nutritive quality of the feed that is available to those subordinate animals which must wait to feed until after the peak feeding period (DeVries et al., 2005; Hosseinkhani et al., 2008). Given the high level of competition (200\% stocking density) and use of 2 heifers per feed bin within the competitive treatment, it is difficult to conclude how these results would translate into a commercial setting with heifers, varying in social status, managed at moderate levels of overstocking at the feed bunk. Further research is therefore needed to assess how moderate overstocking and social status interact to affect feed access and maintenance of nutrient intake in ad libitum and group-fed growing dairy heifers.

\section{CONCLUSIONS}

Competition for feed changes the feeding behavior of growing dairy heifers. These changes include consumption of fewer meals per day that are longer in duration and tend to be larger. Competitively fed heifers also tended to have shorter feeding times, particularly at peak feeding periods. Competition for feed also tended to increase the day-to-day variation in feeding time, meal duration, and meal size. It can be concluded that competition for feed for growing dairy heifers alters feeding patterns, and reduces access to feed, particularly during periods of peak feeding activity, and tends to increase day-to-day variation in feeding behavior.

\section{ACKNOWLEDGMENTS}

We thank the staff and students at The University of British Columbia's Dairy Education and Research Centre. In particular, we thank A. Greter of The University of British Columbia Animal Welfare Program and A. Nadalin of Agriculture and Agri-Food Canada for their technical help throughout the data collection period. This project was funded by the Natural Sciences and Engineering Research Council of Canada and the Dairy Farmers of Canada. 


\section{REFERENCES}

Allen, M. S. 1997. Relationship between fermentation acid production in the rumen and the requirement for physically effective fiber. J. Dairy Sci. 80:1447-1462.

AOAC. 2000. Official Methods of Analysis. 17th ed. Association of Official Analytical Chemists International, Arlington, VA.

Beauchemin, K. A., L. Eriksen, P. Nørgaard, and L. M. Rode. 2008. Salivary secretion during meals in lactating dairy cattle. J. Dairy Sci. 91:2077-2081.

Campling, R. C., and C. A. Morgan. 1981. Eating behavior of housed dairy cows-A review. Dairy Sci. Abstr. 43:57-63.

Canadian Council on Animal Care. 1993. Guide to the Care and Use of Experimental Animals. Vol. 1. E. D. Olfert, B. M. Cross, and A. A. McWilliam, ed. CCAC, Ottawa, Canada.

Chapinal, N., D. M. Veira, D. M. Weary, and M. A. G. von Keyserlingk. 2007. Validation of a system for monitoring individual feeding and drinking behavior and intake in group housed cattle. J. Dairy Sci. 90:5732-5736.

DeVries, T. J., F. Dohme, and K. A. Beauchemin. 2008. Repeated ruminal acidosis challenges in lactating dairy cows at high and low risk for developing acidosis: Feed sorting. J. Dairy Sci. 91:39583967.

DeVries, T. J., M. A. G. von Keyserlingk, and K. A. Beauchemin. 2005. Frequency of feed delivery affects the behavior of lactating dairy cows. J. Dairy Sci. 88:3553-3562.

DeVries, T. J., M. A. G. von Keyserlingk, and D. M. Weary. 2004. Effect of feeding space on the inter-cow distance, aggression, and feeding behavior of free-stall housed lactating dairy cows. J. Dairy Sci. 87:1432-1438.

DeVries, T. J., M. A. G. von Keyserlingk, D. M. Weary, and K. A. Beauchemin. 2003. Measuring the feeding behavior of lactating dairy cows in early to peak lactation. J. Dairy Sci. 86:33543361.

González, L. A., A. Ferret, X. Manteca, J. L. Ruíz-de-la-Torre, S. Calsamiglia, M. Devant, and A. Bach. 2008a. Effect of the number of concentrate feeding places per pen on performance, behavior, and welfare indicators of Friesian calves during the first month after arrival at the feedlot. J. Anim. Sci. 86:419-431.

González, L. A., A. Ferret, X. Manteca, J. L. Ruíz-de-la-Torre, S. Calsamiglia, M. Devant, and A. Bach. 2008b. Performance, behavior, and welfare of Friesian heifers housed in pens with two, four, and eight individuals per concentrate feeding place. J. Anim. Sci. $86: 1446-1458$.

Greter, A. M., T. J. DeVries, and M. A. G. von Keyserlingk. 2008. Nutrient intake and feeding behavior of growing dairy heifers: Effects of dietary dilution. J. Dairy Sci. 91:2786-2795.

Hafez, E. S. E., and M. F. Bouissou. 1975. The behavior of cattle. Pages 203-245 in The Behaviour of Domestic Animals. 3rd ed. E. S. E Hafez, ed. Bailliere Tindall, London, UK.

Hoffman, P. C., N. M. Brehm, S. G. Price, and A. Prill-Adams. 1996 Effect of accelerated postpubertal growth and early calving on lactation performance of primiparous Holstein heifers. J. Dairy Sci. 79:2024-2031.

Hoffman, P. C., C. R. Simson, and M. Wattiaux. 2007. Limit feeding of gravid Holstein heifers: Effect on growth, manure nutrient excretion, and subsequent early lactation performance. J. Dairy Sci. 90:946-954.

Hosseinkhani, A., T. J. DeVries, K. L. Proudfoot, R. Valizadeh, D. M. Veira, and M. A. G. von Keyserlingk. 2008. The effects of feed bunk competition on the feed sorting behavior of close-up dry cows. J. Dairy Sci. 91:1115-1121.

Huzzey, J. M., D. M. Veira, D. M. Weary, and M. A. G. von Keyserlingk. 2007. Prepartum behavior and dry matter intake identify dairy cows at risk for metritis. J. Dairy Sci. 90:3220-3233.

Keys, J. E., R. E. Pearson, and P. D. Thompson. 1978. Effect of feedbunk stocking density on weight gains and feeding behavior of yearling Holstein heifers. J. Dairy Sci. 61:448-454.

Kononoff, P. J., A. J. Heinrichs, and D. R. Buckmaster. 2003. Modification of Penn State forage and total mixed ration particle separator and the effects of moisture content on its measurements. J. Dairy Sci. 86:1858-1863.

Leonardi, C., and L. E. Armentano. 2003. Effect of quantity, quality and length of alfalfa hay on selective consumption by dairy cows. J. Dairy Sci. 86:557-564.

Leonardi, C., and L. E. Armentano. 2007. Feed selection by dairy cows fed individually in a tie-stall or as a group in a free-stall barn. J. Dairy Sci. 90:2386-2389.

Loerch. S. C. 1990. Effects of feeding growing cattle high-concentrate diets at a restricted intake on feedlot performance. J. Anim. Sci. 68:3086-3095.

Longenbach, J. I., A. J. Heinrichs, and R. E. Graves. 1999. Feed bunk length requirements for Holstein dairy heifers. J. Dairy Sci. 82:99-109.

National Research Council. 2001. Nutrient Requirements for Dairy Cattle. Natl. Acad. Sci. Washington, DC

Olofsson, J. 1999. Competition for total mixed diets fed for ad libitum intake using one or four cows per feeding station. J. Dairy Sci. 82:69-79

Owens, F. N., D. S. Secrist, W. J. Hill, and D. R. Gill. 1998. Acidosis in cattle: A review. J. Anim. Sci. 76:275-286.

Pyke, G. H., H. R. Pulliam, and E. L. Charnov. 1977. Optimal foraging: A selective review of theory and tests. Q. Rev. Biol. 52:137-154.

SAS Institute. 2003. User's Guide: Statistics. Version 9.1.3 ed. SAS Institute Inc., Cary, NC.

Tamminga, S. C., J. van der Koelen, and A. M. van Wauren. 1979. Effects of the level of feed intake on nitrogen entering the small intestine of dairy cows. Livest. Prod. Sci. 6:255-262.

Tolkamp, B. J., D. J. Allcroft, E. J. Austin, B. L. Nielsen, and I. Kyriazakis. 1998. Satiety splits feeding behaviour into bouts. J. Theor. Biol. 194:235-250.

Van Soest, P. J., J. B. Robertson, and B. A. Lewis. 1991. Methods for dietary fiber, neutral detergent fiber and nonstarch polysaccharide in relation to animal nutrition. J. Dairy Sci. 74:3583-3597. 